\title{
Measurement of Event-Related Brain Potentials (ERP) Amplitude and Latency Based on Digital Stochastic Measurement over Interval
}

\author{
Djordje Novakovic ${ }^{1}$, Platon Sovilj ${ }^{1}$, Nikola Petrovic ${ }^{1}$, Milan Milovanovic ${ }^{1}$, Jaroslaw Makal ${ }^{2}$, \\ Wojciech Walendziuk ${ }^{2, *}$ \\ ${ }^{1}$ Faculty of Technical Sciences, University of Novi Sad, \\ Trg Dositeja Obradovica 6, Novi Sad 21000, Serbia \\ ${ }^{2}$ Department of Electrical Engineering, Bialystok University of Technology, \\ Wiejska 45D St., 15-351 Bialystok, Poland \\ w.walendziuk@pb.edu.pl
}

\begin{abstract}
In this paper, the measurement of event-related brain potentials (ERP) amplitude and latency based on digital stochastic measurement over interval (DSMI) method are described. Different variations of the measurement system are considered. It was found that measurement errors of amplitude increase with the reduction of the examination time. However, the measurement errors for ERP peak latency remain relatively small. This makes the system useful for practical implementations when the latency is the most interesting parameter and requirements for a short measurement time are of high priority.
\end{abstract}

Index Terms-Analog-digital conversion; Biomedical measurement; Brain: instrumentation and measurement; Neuroscience; Stochastic processes.

\section{INTRODUCTION}

Electroencephalography (EEG) is a measurement method used for measuring brain electrical voltage fluctuations [1]. This method is widely used in detection of neurophysiological phenomena of the central nervous system (CNS). Recording of EEG signals is often used in clinical diagnostics procedures of audio-visual tests [2] or multiphase detection of sleep [3]. Except of the clinical practice, EEG is also used in many research areas [4]-[11]. EEG signals are non-stationary and oscillatory signals [12] originating from the brain electrical potentials, and their amplitudes are less than $300 \mu \mathrm{V}$ [1]. The EEG signal spectrum ranges can be divided into five ranges: delta (from $1 \mathrm{~Hz}$ to $4 \mathrm{~Hz}$ ), theta (from $4 \mathrm{~Hz}$ to $8 \mathrm{~Hz}$ ), alpha (from $8 \mathrm{~Hz}$ to $12 \mathrm{~Hz}$ ), beta (from $12 \mathrm{~Hz}$ to $30 \mathrm{~Hz}$ ), and gamma ( $\geq$ $30 \mathrm{~Hz}$ ) [12].

The term "event-related potentials" (ERP) was used for the first time by Herb Vaughan in 1969 [12]. Brain electrical activities are evoked by a stimulus (evoked potentials), and these appear during intended movements and other

Manuscript received 11 September, 2019; accepted 16 February, 2020.

This research was funded by a Visegrad Scholarship Grant (No. 51910674). This research was performed in cooperation with the University of Novi Sad (Serbia) and Bialystok University of Technology (Poland). psychological processes relatively independent from stimuli, were named by this term [12].

Nowadays, the ERP measurement method has many various applications in the clinical practice [13], [14], in research of the cognitive neuroscience [15]-[17], and in research and development of Brain Computer-Interface (BCI) systems [18]-[20].

Usual measurement of the ERP signal requires presenting tens or thousands stimuli and the acquisition of the EEG epochs related to individual stimuli [12]. This large number of EEG epochs is necessary to eliminate the spontaneous part of the EEG signal (in which typical EEG frequency bands dominate) and to extract the ERP signal as a nonspontaneous part of the EEG signal, through the process of averaging EEG epochs samples [12]. There are many research efforts directed towards decreasing the number of required EEG epochs (even towards obtaining a single-trial ERP measurement) based on some parametric method approaches [20]-[22]. However, these approaches still lack the accuracy required for practical ERP measurement tasks.

Various measurement methods based on an approach named "digital stochastic measurement over interval" were developed in the past. This approach has its roots in the research of the reliable operating instruments with an inherent random error [23], and in the research of adding a random uniform dither to an A/D converter input [24], [25]. The evolution of these methods can be followed in [26][33]. The digital stochastic measurement of signal RMS (Root Mean Square) over interval was proposed in [26], [27] and further improved in [29]. The digital stochastic measurement of signal harmonics over interval was developed and reported in [28]. The digital stochastic measurement of a non-stationary signal over interval emphasizing an EEG signal measurement example was introduced in [31]. Finally, the latest achievements of the digital stochastic measurement methods over interval were described in [31]-[33].

Continuing with the findings in [30], in this paper, measuring the ERP amplitude and the latency based on the DSMI method were investigated. The possibility of reducing 
the number of epochs necessary for such measurement is emphasized in this investigation. The research includes the development of the concept of the digital stochastic measurement over interval (DSMI) method implementation in the measurement of the ERP amplitude and latency, and the simulation of the measurement system modeled according to this concept and implemented in MATLAB. The input data for the simulation were selected from [34]. During the research, a possibility of reducing the number of epochs was discovered, which results in reducing the time of measurement.

\section{The METHOD AND THE MEASUREMENT SySTEM}

\section{A. DSMI Method}

The DSMI method is based on using an analog adder for adding a uniform dithering signal $h(t)$ to the original signal $y(t)$ and an analog-to-digital converter (ADC) (Fig. 1) [26][29].

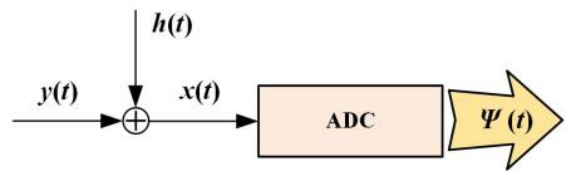

Fig. 1. Input of basic DSMI instrument.

According to [26], the DSMI instrument, in its basic form, measures the averaged value $m_{y}$ of the signal $y(t)$ over interval $[0, T]$

$$
m_{y}=\frac{1}{T} \times \int_{0}^{T} y(t) \times d t
$$

The dither stochastic signal $h(t)$ is defined by Widrow's condition

$$
0 \leq|h| \leq \frac{a}{2}
$$

where $a$ is quantum voltage of ADC, and the probability density function $p$ of $h(t)$ is defined with

$$
p(h)=\frac{1}{a}
$$

The averaged value of the ADC output signal for the finite number of dithered samples $N$ over $[0, T]$ is

$$
\bar{\Psi}=\frac{1}{N} \times \sum_{i=1}^{N} \Psi_{i}
$$

In [26], [27] it is described how the DSMI instrument for measuring the effective value of signal could be designed. The design of the DSMI instrument for measuring harmonics of a compound signal (even when Signal-to-Noise Ratio is very small) is presented in [27], [28]. The compound signal $s(t)$ with the fundamental period $T$ can be expressed as

$$
s(t)=F_{a 0}+\sum_{k=1}^{H} F_{a k} \times \cos \left(k \omega_{0} t\right)+\sum_{k=1}^{H} F_{b k} \times \sin \left(k \omega_{0} t\right),
$$

where $\omega_{0}=\frac{2 \times \pi}{T}, k$ is order of harmonics, $F_{a 0}$ is DC component, and $F_{a k}$ and $F_{b k}$ are cosine and sine Fourier coefficients, respectively.

In the DSMI instrument for the harmonics measurement, $F_{a 0}, F_{a k}$, and $F_{b k}$ are measured. The method of measurement of one Fourier coefficient is illustrated in Fig. 2.

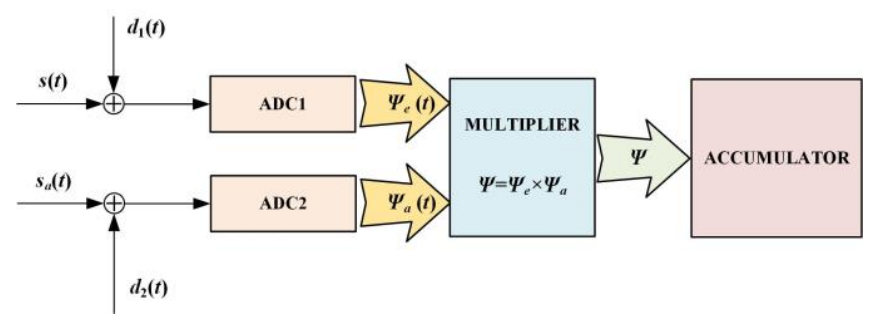

Fig. 2. The schematic diagram of measurement of one Fourier coefficient.

The signal $s_{a}(t)$ is a dithered auxiliary based on the cosine or sine function. For measuring $k^{\text {th }}$ cosine Fourier coefficient, $s_{a}(t)$ is

$$
s_{a}(t)=s_{a \cos k}(t)=R \times \cos \left(k \omega_{0} t\right)
$$

and for measuring $k^{\text {th }}$ sine Fourier coefficient, $s_{a}(t)$ is

$$
s_{a}(t)=s_{a \sin k}(t)=R \times \sin \left(k \omega_{0} t\right),
$$

where $R$ is the amplitude of these auxiliary signals. The probability density functions $p_{1,2}$ and amplitudes of the uniform dither signals $d_{1,2}$ are defined as follows

$$
p\left(d_{1,2}\right)=\frac{1}{\Delta_{1,2}}, 0 \leq\left|d_{1,2}\right| \leq \frac{\Delta_{1,2}}{2},
$$

where $\Delta_{1,2}$ are quantum voltages of $\mathrm{ADC} 1$ and $\mathrm{ADC} 2$, respectively.

The input $s(t)$ and auxiliary $s_{a}(t)$ signals are sampled with a sample frequency $f_{s} \geq 2 \times f_{\max }$, where $f_{\max }$ is maximum frequency of the input signal $s(t)$ (Nyquist sampling criterion). In [28], it is shown that:

$$
\left\{\begin{array}{l}
F_{a k}=\frac{2 \times \bar{\Psi}_{\cos k}}{R}, \\
F_{b k}=\frac{2 \times \bar{\Psi}_{\sin k}}{R},
\end{array}\right.
$$

and the way of controlling the errors of $F_{a k}$ and $F_{b k}$ measurements is described. $\bar{\Psi}_{\cos k}$ is the averaged output of accumulator when the cosine Fourier coefficient is measured, and $\bar{\Psi}_{\sin k}$ is the averaged output of accumulator when the sine Fourier coefficient is measured.

If the DSMI instrument is designed to measure $N_{H}$ harmonics, then the instrument should have $2 \times N_{H}+1$ multipliers and $2 \times N_{H}+1$ accumulators. This hardware could be very complex if the blocks from Fig. 2 were just multiplied. However, the DSMI instrument with simpler hardware is designed [29] based on memory for a generation of pseudo dithered components $\Psi \mathrm{a}$ and FPGA (field 
programmable gate array) structure instead of multipliers and accumulators (Fig. 3).

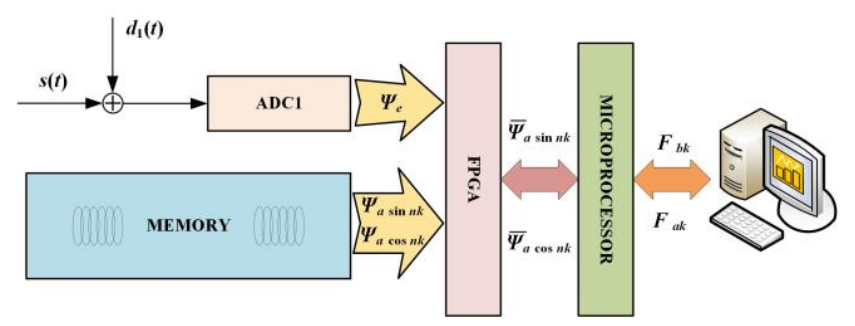

Fig. 3. DSMI instrument for harmonics measurement connected with PC.

In [30], it is shown how the instrument from Fig. 3 can be also used for the digital stochastic measurement over interval of a non-stationary signal, which was elaborated with a case of the EEG signal measurement by this instrument.

\section{B. Measurement System Based on DSMI Method}

A standard system for measurement of the ERP peak amplitude and latency demands a relatively large number of EEG epochs (from 100 to 300 or even more) [12]. Usual duration of one EEG measurement interval (one interval includes one epoch) lasts from $1 \mathrm{~s}$ to $8 \mathrm{~s}$ [12], so a complete measurement can take up to 40 minutes, which is rather a long time.

We propose a system for measuring ERP peak amplitudes and latencies based on the DSMI method with the same or reduced number of measurement epochs compared with the standard system. Obviously, reductions of the measurement epochs number consequently reduce the total measurement time. The block diagram of the system is shown in Fig. 4.
The DSMI module from Fig. 4 has the same structure as the instrument shown in Fig. 3. The conditioning module from Fig. 4 plays the role of the conditioning low-level EEG signal to the input range of the DSMI module, and this module is the same as in the standard measurement system.

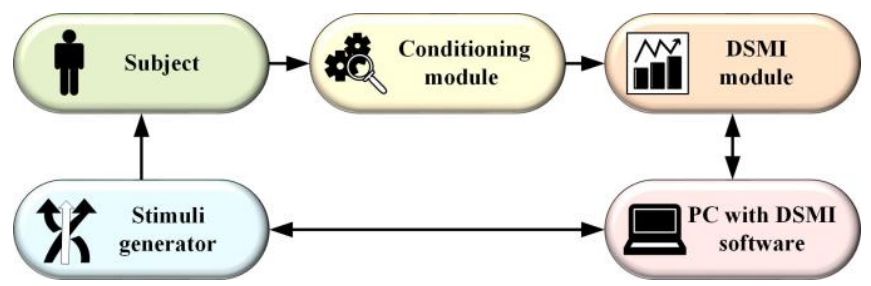

Fig. 4. Block diagram of the measurement system based on DSMI method.

\section{Model for Simulation of the Measurement System and Comparison}

The block diagram of the model for simulation of the proposed measurement system and comparison of the measurement results with the referential data are shown in Fig. 5.

The input EEG signal is generated from the data taken from a database, which contains records of EEG signals and events. The recorded results are organized into parcels, and each parcel contains $N_{e} / b r s k$ epochs, where $N_{e}$ is the total number of epochs and brsk is the total number of parcels.

Samples of recorded EEG signals from the database are stored into an Excel file and prepared for processing with EEGLAB [35]. EEGLAB is a MATLAB toolbox for processing data from EEG and other electrophysiological signals, and magnetoencephalography (MEG) signals.

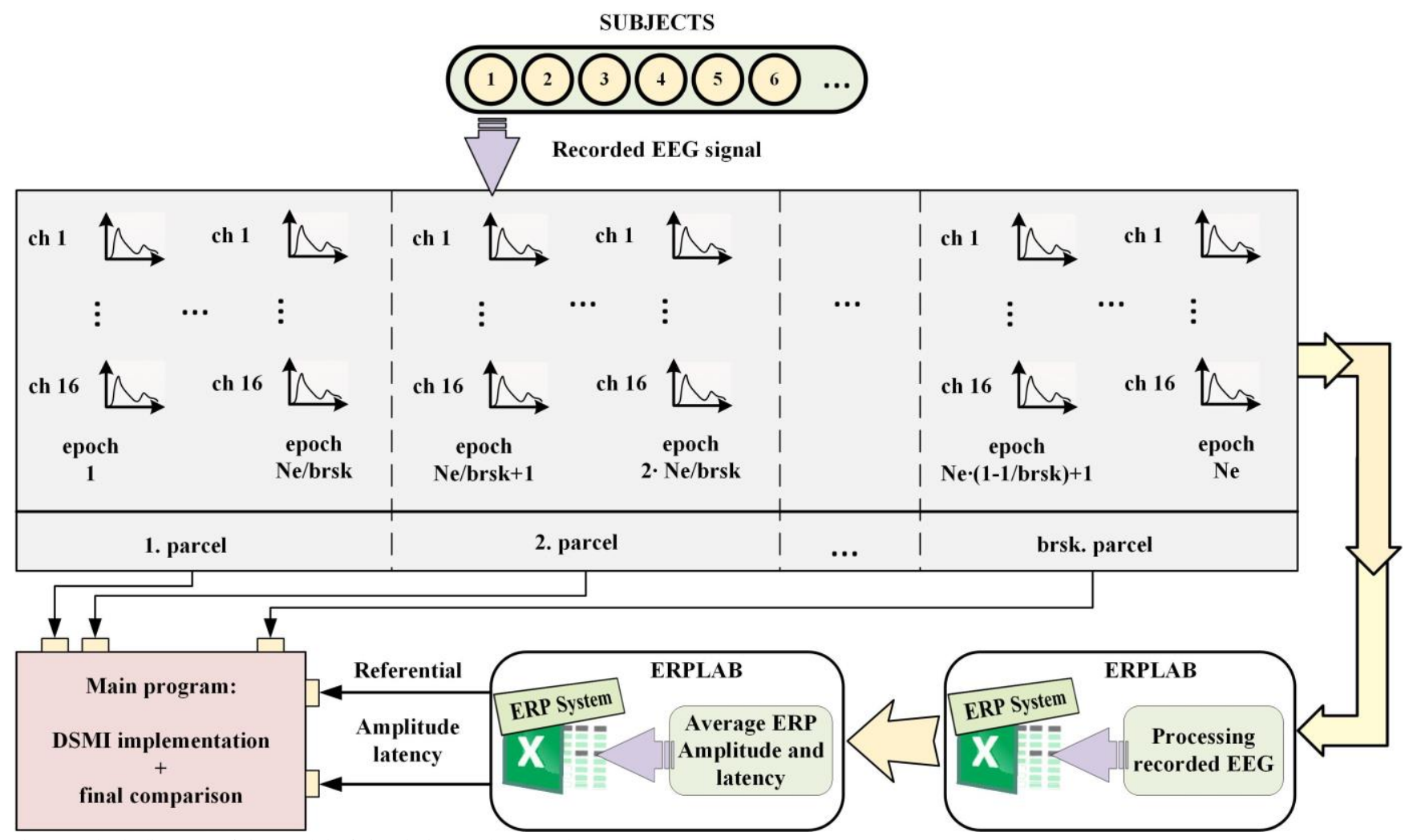

Fig. 5. Block diagram of the model of simulation and comparison. 


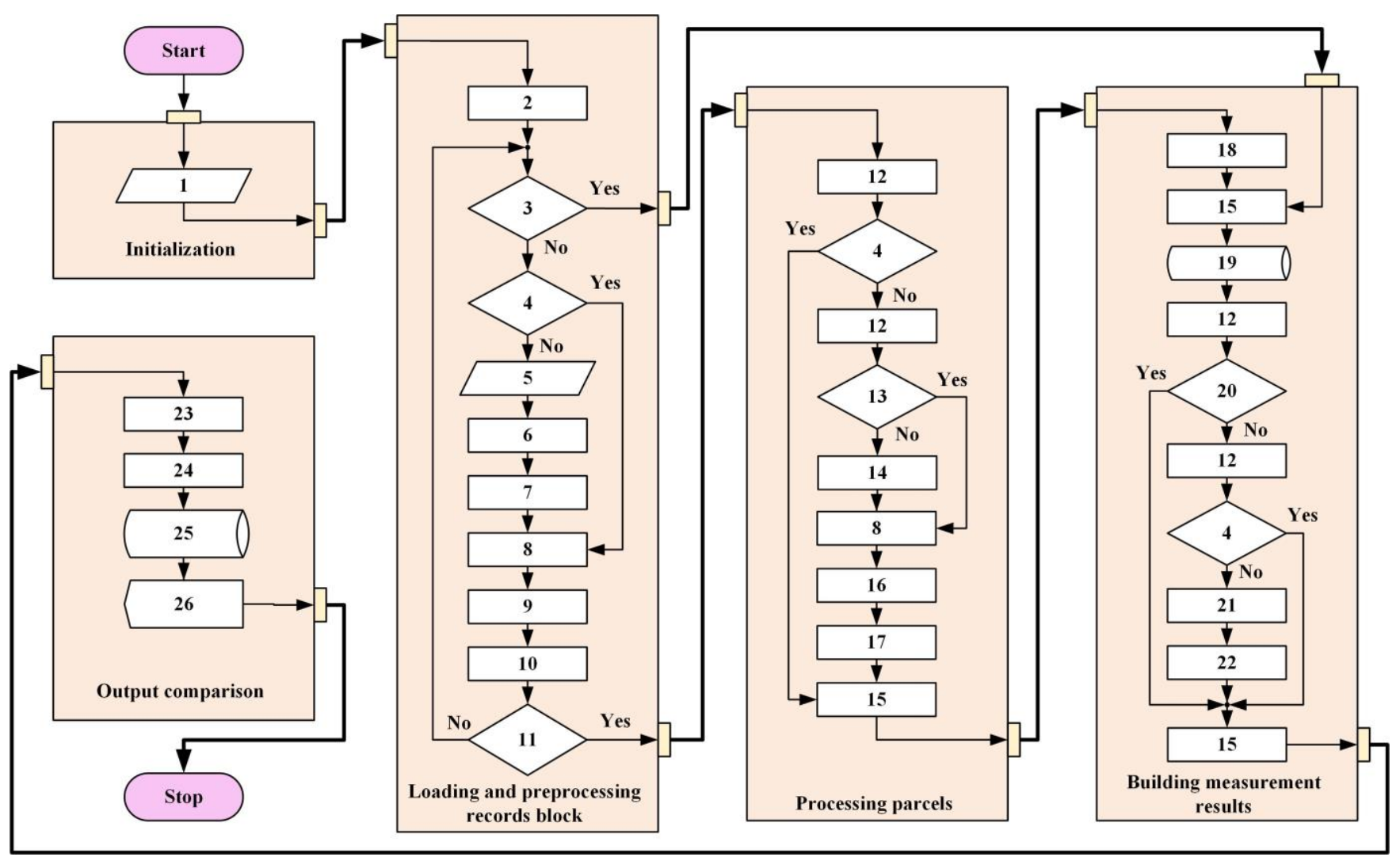

Fig. 6. Flow diagram of the algorithm of the main program. Blocks in the diagram are described in Table I.

The averaged ERP amplitude and latency are calculated by ERPLAB [36] from all the epochs, thus making the referential ERP amplitude and latency necessary for the comparison. ERPLAB is a MATLAB toolbox for analysing ERP data and it is tightly integrated with the EEGLAB toolbox extending EEGLAB capabilities to provide tools for ERP processing, visualization, and analysis.

The conditioning module and the DSMI module are simulated by the main program (developed in MATLAB). The comparison of the measurement results with the referential data is performed by the main program too. A flow diagram of the algorithm of the main program is presented in Fig. 6 and Table I.

In the further part of this section, most important variables and relations used in the main program are shown and described. At first, the conditioning module amplifies the EEG samples by factor $K$, thus enables better covering of the input range of ADC1 in the DSMI module (Fig. 2). Because each EEG sample $u_{e}$ is expressed in microvolts, an amplified EEG sample prs is simply calculated from

$$
\text { prs }=K \times u_{e} \times 10^{-6} \mathrm{~V} .
$$

Each epoch consists of $N$ samples, and if one epoch duration is $T$, then the sampling period $T_{s}=T / N$ and the sampling frequency $f_{s}=1 / T_{s}$. The base frequency of sine/cosine function is $f=1 / T=1 \mathrm{~Hz}$ and the auxiliary sine signal sas, according to (7), is calculated by

$$
\operatorname{sas}=R \times \sin \left(2 \pi k f T_{s}\right) .
$$

The dither signal $d 2 s$ is defined with

$$
d 2 s=(-1) \times M A X G R E S 2+\operatorname{rand} \times \text { DELTA } 2,
$$

where rand is MATLAB function and MAXGRES2 is maximum of the quantization error of ADC2 (Fig. 2), which is defined with

$$
M A X G R E S 2=\frac{D E L T A 2}{2},
$$

and DELTA2 $=0.019608 \mathrm{~V}$ is $\mathrm{ADC} 2$ resolution. The dithered auxiliary sine function xas is formed with

$$
x a s=s a s+d 2 s .
$$

The auxiliary cosine function $x a c$ is generated in a similar way ( $s a c$ is auxiliary cosine signal):

$$
\begin{gathered}
s a c=R \times \cos \left(2 \pi k f T_{s}\right), \\
x a c=s a c+d 2 s .
\end{gathered}
$$

The input of ADC1 is the signal $r x$ calculated by adding a stochastically uniform dither signal $d_{l}$

$$
d_{1}=(-1) \times M A X G R E S 1+\operatorname{rand} \times \text { DELTA1, }
$$

where MAXGRES1 is maximum of the quantization error of ADC1, which is described with

$$
M A X G R E S 1=\frac{D E L T A 1}{2},
$$

and DELTA $1=0.079365 \mathrm{~V}$ is $\mathrm{ADC} 1$ resolution. Thus, the input of ADC1 is calculated by

$$
r x=p r s+d 1 .
$$


TABLE I. DESCRIPTION OF THE BLOCKS FROM THE FLOW DIAGRAM OF THE ALGORITHM PRESENTED IN FIG. 6.

\begin{tabular}{|c|c|}
\hline Block & Description \\
\hline 1 & Call subroutine with initial parameters \\
\hline 2 & Start the loop through the all epochs \\
\hline 3 & The current epoch is the last epoch? \\
\hline 4 & The current sample is the last sample in the current epoch? \\
\hline 5 & Load the next samples from EEG records \\
\hline 6 & $\begin{array}{l}\text { Extend the vector of amplified EEG samples with the } \\
\text { current sample amplified }\end{array}$ \\
\hline 7 & Add the current sample to DSMI procedure \\
\hline 8 & The end of the current epoch \\
\hline 9 & Calculation of Fourier coefficients \\
\hline 10 & Build the vector of measurement results in time-domain \\
\hline 11 & The current epoch is the last one in the selected parcel? \\
\hline 12 & Start the loop through the epochs in the parcel \\
\hline 13 & The current epoch is the last one in the parcel? \\
\hline 14 & Calculate next average sample \\
\hline 15 & End the loop through the epochs in the parcel \\
\hline 16 & Build the vector of averaged samples in the parcel \\
\hline 17 & Find the peak and its amplitude and latency time \\
\hline 18 & $\begin{array}{l}\text { Build the vector of peak amplitudes and latency times of } \\
\text { the parcels }\end{array}$ \\
\hline 19 & Store the vector into file system \\
\hline 20 & The current parcel is the last one? \\
\hline 21 & Build the vector of referential averaged samples \\
\hline 22 & Build the vector of errors for all measured samples \\
\hline 23 & Determination of referential amplitude and latency time \\
\hline 24 & $\begin{array}{l}\text { Calculate the errors of measurement of peak amplitudes and } \\
\text { latency times for all parcels }\end{array}$ \\
\hline 25 & $\begin{array}{l}\text { Storing the errors of measurement of peak amplitudes and } \\
\text { latency times for all parcels into file system }\end{array}$ \\
\hline 26 & Display measured results vs. referential data \\
\hline
\end{tabular}

For each of the selected epochs, the DC component $(R M)$ and the cosine and sine Fourier coefficients $\left(F_{a c}, F_{b s}\right)$ are measured. The coefficients are indexed with $k=1,2, \ldots, H$ ( $H$ is the highest coefficient index included in the measurement).

One basic measurement interval is equal to one epoch duration $T=1 \mathrm{~s}$, so we can use the measured parameters $R M, F_{a c}$, and $F_{b s}$ as the results of the discrete Short-time Fourier Transform (STFT) for further calculation of the resulting time series. Thus, the measurement result in the time domain $r s e(t)$ can be calculated by

$$
\begin{aligned}
r s e(t)= & R M+\sum_{k=1}^{H} F_{a c} \times \cos \left(2 \times \pi \times k \times f \times T_{s}\right)+\ldots \\
& \ldots+\sum_{k=1}^{H} F_{b s} \times \sin \left(2 \times \pi \times k \times f \times T_{s}\right) .
\end{aligned}
$$

The measurement result for one epoch is stored in a vector variable consisting of $N$ values. Each selected epoch has such a vector, and all those vectors are averaged resulting in the vector of the averaged samples. The sample with the maximum of amplitude ampmax presents the ERP component peak and latmax presents the time when the peak appeared during the basic measurement interval.

The simulation covered different cases of selected epochs, and all the resulting peaks amplitudes and peaks latency times are stored into vector variables MAMP and MLAT, respectively. These amplitudes and latency times are compared with the referential data.

The measurement errors are calculated as the differences between the referential and the measured data. The vector of measurement errors for peak amplitudes is calculated from

$$
\text { grampl }=R A M P-M A M P \mathrm{~V},
$$

where $R A M P$ is the vector of referential peak amplitudes. The vector of measurement errors for peak latencies is calculated from

$$
\text { grlat }=R L A T-M L A T \mathrm{~V},
$$

in which RLAT is a vector of the referential peak latencies.

\section{RESUlts}

The database from [21] is used for generating the input EEG signal. Reference [34] contains records of EEG signal measured by 16 channels for various subjects. The input EEG signal is generated from the recorded results of the subject named " $\mathrm{S}_{1}$ " in [34].

The input EEG signal data are divided into 256 EEG epochs $\left(N_{e}=256\right)$ recorded during one type of central nervous system stimulation. Each epoch consists of 500 samples $(N=500)$, and one epoch duration is $T=1 \mathrm{~s}$ resulting in the sampling frequency of $f_{s}=500 \mathrm{~Hz}$ (i.e., EEG signal is sampled every $T_{s}=2 \mathrm{~ms}$ ). Consequently, the total number of samples for 16 channels is $16 \times N_{e} \times N=$ 2048000.

The averaged samples for all 16 channels are shown in Fig. 7. Measurements from all 16 channels are the input channels for simulation. However, a channel contains measurements from PZ location, which is one of frequently used locations for obtaining ERP components [5], and the steps of obtaining the results concerning this location are presented with all details. These steps are applied for all the other channels too.

The averaged samples for channel 13 are shown in Fig. 8. The referential values of the ERP component peak amplitude and latency are $V_{r e f}=4.36 \mu \mathrm{V}$ and $t_{\text {lat }}=528.72 \mathrm{~ms}$, respectively.

The parameters of the simulated measurement system are shown in Table II. The variable number of the measured harmonics covered the values from the set of 2 values $\{30$; $15\}$, and the variable number of the epochs included in the measurement covered the set of 4 values $\{256 ; 32 ; 25 ; 16\}$. Consequently, the simulation covered $2 \times 4=8$ different designs of the measurement system. 

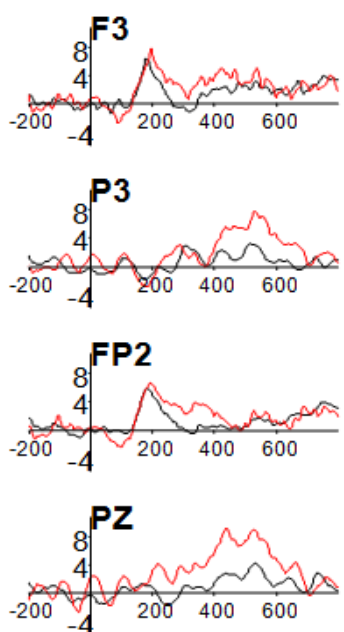
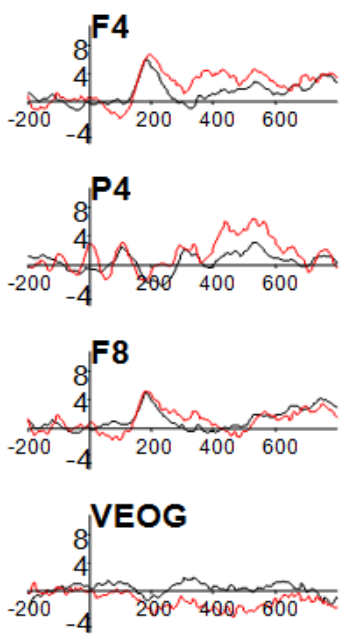
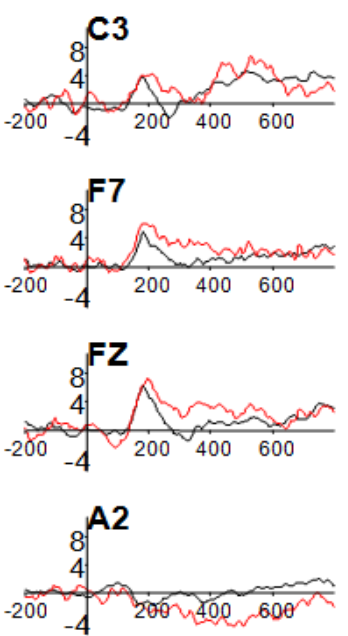
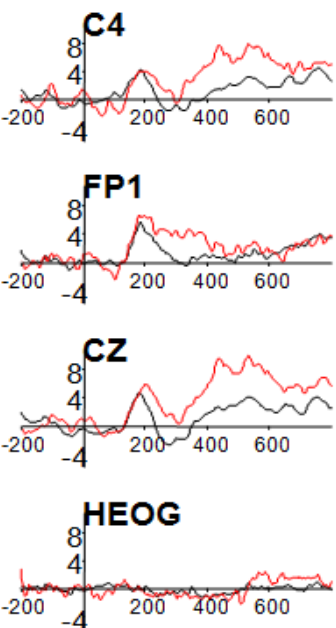

Fig. 7. The averaged samples of ERP at various locations. Deviant stimuli ERP samples (which are always in focus of ERP method) are presented in red colour.

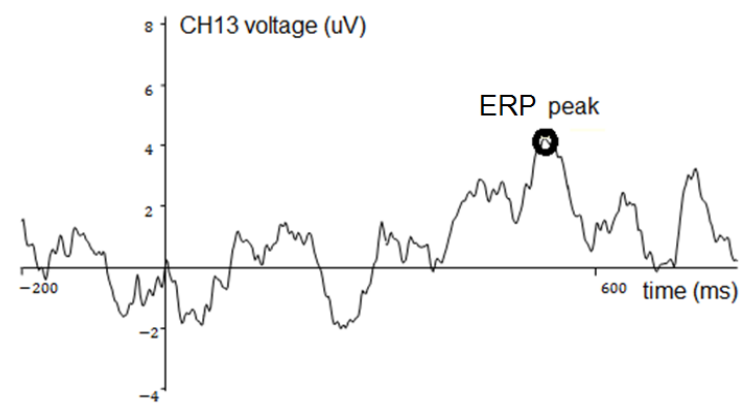

Fig. 8. The averaged samples of channel 13 (PZ location) with marked ERP peak.

TABLE II. THE PARAMETERS OF THE MEASUREMENT SYSTEM.

\begin{tabular}{|c|c|}
\hline Parameter & Value \\
\hline Input channel & $13(\mathrm{PZ})$ \\
\hline Epoch duration $-T(\mathrm{~s})$ & 1 \\
\hline Number of samples per epoch $-N$ & 500 \\
\hline Sampling period $-T_{s}(\mathrm{~ms})$ & 2 \\
\hline Sampling frequency $-T_{s}(\mathrm{~Hz})$ & 500 \\
\hline Conditioning module gain $-K$ & $10^{5}$ \\
\hline Auxiliary signal amplitude $-R(\mathrm{~V})$ & 1 \\
\hline Input range of ADC1 and ADC2 & {$[-2.5 \mathrm{~V},+2.5 \mathrm{~V}]$} \\
\hline Total number of epochs $-N_{e}$ & 256 \\
\hline $\begin{array}{c}\text { Variation of the number of measured harmonics } \\
-H\end{array}$ & $\{30 ; 15\}$ \\
\hline $\begin{array}{c}\text { Variations of the number of epochs included in } \\
\text { the measurement }\end{array}$ & $\{256 ; 32 ; 25 ; 16\}$ \\
\hline
\end{tabular}

The results of the design with 30 harmonics (DC component, 30 sine coefficients, and 30 cosine coefficients are measured) and all the epochs included are presented in Fig. 9. In this design, the measurement error of the ERP peak time latency, relative to the referential latency time, is $1.51 \%$ (Table III). The measurement error of the ERP peak amplitude, relative to the signal range, is $12.34 \%$.

The results of the design with 15 harmonics and all the epochs included are shown in Fig. 10. In this design, the measurement error of the ERP peak time latency, relative to referential latency time, is $1.52 \%$ (Table III). The measurement error of the ERP peak amplitude, relative to the signal range, is $13.62 \%$. Table IV summarizes measurement errors for all other channels/locations (from $\mathrm{F}_{\mathrm{P} 1}$ to $\left.\mathrm{H}_{\mathrm{EOG}}\right)$.
From those results, it can be concluded that the measurement errors decrease with the extension of the measured harmonics number. Moreover, the relative error is lower for the peak latency measurement comparing to the peak amplitude measurement.

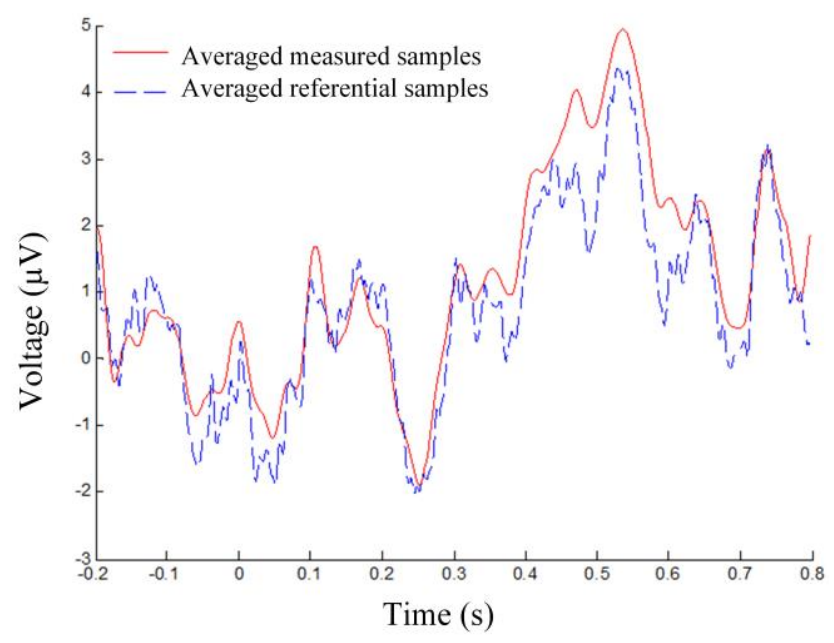

Fig. 9. Averaged measured samples vs. averaged referential samples (PZ location). Number of measured harmonics is $H=30$, and measurement included all the epochs.

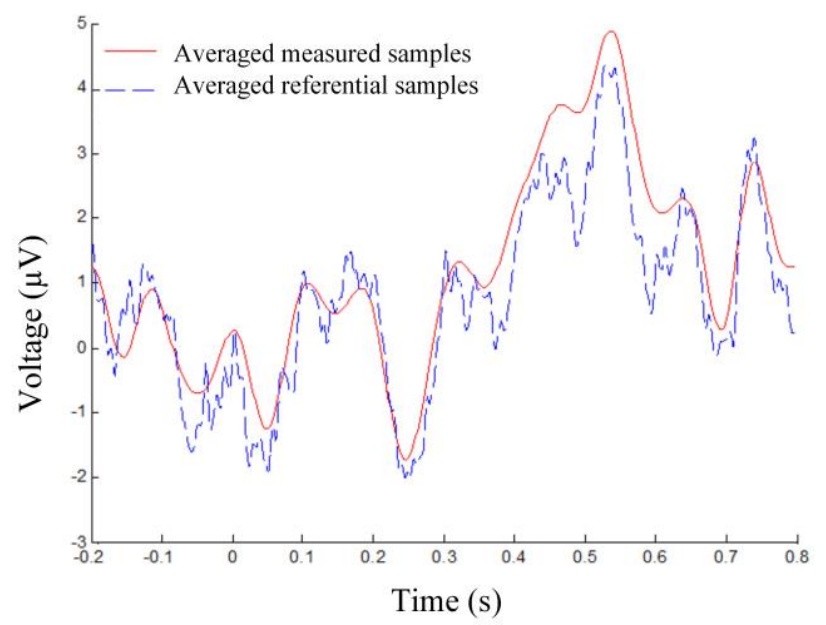

Fig. 10. Averaged measured samples vs. averaged referential samples (PZ location). Number of measured harmonics is $H=15$, and measurement included all the epochs. 
In Tables IV-VI, the results for both designs (30 and 15 harmonics measured by DSMI module) are presented, but with the reduced number of epochs, included into the measurement. They result in reducing the total measurement time.

This reduction is numerically described with the ratio of the measurement time reduction, which is calculated as a ratio between the total measurement time when all epochs are included and a ratio when the reduced number of epochs is included into the measurement.

TABLE III. PZ LOCATION MEASUREMENT ERRORS FOR H $=15$ AND $\mathrm{H}=30$ WHEN ALL EPOCHS ARE INCLUDED IN

MEASUREMENT (THERE IS NO REDUCTION OF MEASUREMENT TIME COMPARING TO STANDARD MEASUREMENT METHOD). H IS THE NUMBER OF HARMONICS MEASURED BY DSMI MODULE.

\begin{tabular}{|c|c|}
\hline \multicolumn{2}{|c|}{ Measurement errors by number of harmonics } \\
\hline \multicolumn{2}{|c|}{$\boldsymbol{H}=\mathbf{1 5}$} \\
\hline Relative error of latency time (\%) & 1.52 \\
\hline Relative error of amplitude (\%) & 13.66 \\
\hline $\boldsymbol{H}=\mathbf{3 0}$ & 1.51 \\
\hline Relative error of latency time (\%) & 12.47 \\
\hline Relative error of amplitude (\%)
\end{tabular}

From last results, it can be concluded that measurement errors decrease with the increase of the number of the measured harmonics too, but also that the measurement errors increase with the increase of the reduction ratio. However, the measurement errors for the peak latency times are relatively small comparing to the measurement errors for the peak amplitude, thus making this approach appropriate for practical implementations when latency is a more interesting parameter than the amplitude and the requirements for a short measurement time are of high priority.

\section{DISCUSSION}

A new system has been presented for measurement of ERP amplitude and latency time based on the digital stochastic measurement over interval.

Previous research on the DSMI method showed that the basic DSMI instrument could be extended for the measurement of one Fourier coefficient. Furthermore, it leads to the development of very accurate instruments for measuring various stationary and non-stationary signals using FPGA structures and memory instead of auxiliary A/D converters.

The new measurement system includes a DSMI module and DSMI software instead of a typical digital measurement module and typical measurement software. A simulation model, for investigating the measurement system, has been developed. This model simulates the functioning of the measurement system and compares the measurement results with the referential data.

TABLE IV. MEASUREMENT ERRORS FOR $\mathrm{H}=15$ AND $\mathrm{H}=30$ WHEN ALL EPOCHS ARE INCLUDED IN MEASUREMENT (LOCATIONS: FP1, FP2, FZ, F3, F4, F7, F8, CZ, C3, C4, P3, P4, A2, VEOG, AND HEOG).

\begin{tabular}{|c|c|c|c|}
\hline $\begin{array}{c}\text { Number of } \\
\text { harmonics } \\
\text { measured by } \\
\text { DSMI module }\end{array}$ & $\begin{array}{c}\text { Measurement } \\
\text { location }\end{array}$ & $\begin{array}{c}\text { Relative } \\
\text { error of } \\
\text { latency time } \\
(\%) \\
\end{array}$ & $\begin{array}{c}\text { Relative error } \\
\text { of amplitude } \\
(\%)\end{array}$ \\
\hline 15 & FP1 & 1.51 & 13.85 \\
\hline 30 & FP1 & 1.48 & 13.75 \\
\hline 15 & FP2 & 1.54 & 14.29 \\
\hline 30 & FP2 & 1.51 & 12.24 \\
\hline 15 & $\mathrm{FZ}$ & 1.55 & 14.55 \\
\hline 30 & FZ & 1.54 & 11.76 \\
\hline 15 & F3 & 1.60 & 14.63 \\
\hline 30 & $\mathrm{~F} 3$ & 1.58 & 12.58 \\
\hline 15 & $\mathrm{~F} 4$ & 1.57 & 14.55 \\
\hline 30 & $\mathrm{~F} 4$ & 1.56 & 12.29 \\
\hline 15 & $\mathrm{~F} 7$ & 1.49 & 13.86 \\
\hline 30 & F7 & 1.48 & 12.41 \\
\hline 15 & F8 & 1.50 & 12.74 \\
\hline 30 & F8 & 1.48 & 12.15 \\
\hline 15 & $\mathrm{CZ}$ & 1.57 & 12.70 \\
\hline 30 & $\mathrm{CZ}$ & 1.56 & 11.43 \\
\hline 15 & $\mathrm{C} 3$ & 1.53 & 14.35 \\
\hline 30 & $\mathrm{C} 3$ & 1.50 & 11.43 \\
\hline 15 & $\mathrm{C} 4$ & 1.54 & 13.06 \\
\hline 30 & $\mathrm{C} 4$ & 1.54 & 10.09 \\
\hline 15 & $\mathrm{P} 3$ & 1.53 & 14.30 \\
\hline 30 & P3 & 1.52 & 13.34 \\
\hline 15 & $\mathrm{P} 4$ & 1.55 & 14.25 \\
\hline 30 & $\mathrm{P} 4$ & 1.55 & 12.43 \\
\hline 15 & $\mathrm{~A} 2$ & 1.53 & 13.31 \\
\hline 30 & $\mathrm{~A} 2$ & 1.50 & 11.82 \\
\hline 15 & VEOG & 1.52 & 14.19 \\
\hline 30 & VEOG & 1.51 & 12.45 \\
\hline 15 & HEOG & 1.56 & 12.71 \\
\hline 30 & HEOG & 1.54 & 11.38 \\
\hline
\end{tabular}

TABLE V. MEASUREMENT ERRORS AND REDUCTION OF MEASUREMENT TIME WHEN REDUCED NUMBER OF EPOCHS IS INCLUDED IN MEASUREMENT (THERE IS REDUCTION OF MEASUREMENT TIME COMPARING TO STANDARD MEASUREMENT METHOD). H IS THE NUMBER OF HARMONICS MEASURED BY DSMI MODULE (LOCATIONS: PZ, FP1, FP2, FZ, F3, F4, F7, F8, AND CZ).

\begin{tabular}{|c|c|c|c|c|c|c|c|}
\hline $\begin{array}{l}\text { Measuremen } \\
\text { t location }\end{array}$ & $\begin{array}{l}\text { Number of } \\
\text { harmonics } \\
\text { measured by } \\
\text { DSMI module }\end{array}$ & $\begin{array}{c}\text { Number of } \\
\text { epochs }\end{array}$ & $\begin{array}{c}\text { Ratio of } \\
\text { measurement } \\
\text { time reduction }\end{array}$ & $\begin{array}{c}\text { Average } \\
\text { relative error } \\
\text { of latency } \\
(\%)\end{array}$ & $\begin{array}{c}\text { Standard } \\
\text { deviation of } \\
\text { relative error } \\
\text { of latency }(\%)\end{array}$ & $\begin{array}{c}\text { Average relative } \\
\text { error of amplitude } \\
(\%)\end{array}$ & $\begin{array}{c}\text { Standard } \\
\text { deviation of } \\
\text { relative error } \\
\text { of amplitude } \\
(\%)\end{array}$ \\
\hline \multirow{6}{*}{ PZ } & \multirow{3}{*}{30} & 32 & 8.00 & 4.21 & 5.33 & 38.62 & 25.29 \\
\hline & & 25 & 10.24 & 5.49 & 5.34 & 46.05 & 33.27 \\
\hline & & 16 & 16.00 & 6.37 & 5.59 & 76.15 & 51.82 \\
\hline & \multirow{3}{*}{15} & 32 & 8.00 & 4.45 & 5.70 & 40.79 & 27.77 \\
\hline & & 25 & 10.24 & 5.98 & 6.01 & 56.09 & 38.47 \\
\hline & & 16 & 16.00 & 7.86 & 6.37 & 84.68 & 53.05 \\
\hline \multirow{3}{*}{ FP1 } & \multirow{3}{*}{30} & 32 & 8.00 & 4.15 & 3.95 & 37.19 & 26.12 \\
\hline & & 25 & 10.24 & 5.10 & 5.38 & 45.59 & 32.96 \\
\hline & & 16 & 16.00 & 6.19 & 6.30 & 74.18 & 49.28 \\
\hline
\end{tabular}




\begin{tabular}{|c|c|c|c|c|c|c|c|}
\hline $\begin{array}{c}\text { Measuremen } \\
\text { t location }\end{array}$ & $\begin{array}{l}\text { Number of } \\
\text { harmonics } \\
\text { measured by } \\
\text { DSMI module }\end{array}$ & $\begin{array}{c}\text { Number of } \\
\text { epochs }\end{array}$ & $\begin{array}{c}\text { Ratio of } \\
\text { measurement } \\
\text { time reduction }\end{array}$ & $\begin{array}{c}\text { Average } \\
\text { relative error } \\
\text { of latency } \\
(\%)\end{array}$ & $\begin{array}{c}\text { Standard } \\
\text { deviation of } \\
\text { relative error } \\
\text { of latency }(\%)\end{array}$ & $\begin{array}{c}\text { Average relative } \\
\text { error of amplitude } \\
(\%)\end{array}$ & $\begin{array}{c}\text { Standard } \\
\text { deviation of } \\
\text { relative error } \\
\text { of amplitude } \\
(\%)\end{array}$ \\
\hline & \multirow{3}{*}{15} & 32 & 8.00 & 4.38 & 4.31 & 40.22 & 27.72 \\
\hline & & 25 & 10.24 & 5.73 & 5.79 & 58.22 & 39.34 \\
\hline & & 16 & 16.00 & 7.32 & 7.45 & 87.31 & 50.86 \\
\hline \multirow{6}{*}{ FP2 } & \multirow{3}{*}{30} & 32 & 8.00 & 3.92 & 4.18 & 39.49 & 25.11 \\
\hline & & 25 & 10.24 & 5.05 & 4.98 & 46.05 & 34.52 \\
\hline & & 16 & 16.00 & 5.87 & 6.11 & 73.40 & 53.69 \\
\hline & & 32 & 8.00 & 4.03 & 4.01 & 40.53 & 27.52 \\
\hline & 15 & 25 & 10.24 & 5.57 & 5.76 & 57.81 & 39.89 \\
\hline & & 16 & 16.00 & 7.49 & 7.85 & 83.49 & 52.21 \\
\hline & & 32 & 8.00 & 3.99 & 3.99 & 39.74 & 24.30 \\
\hline & 30 & 25 & 10.24 & 5.36 & 5.42 & 45.91 & 31.90 \\
\hline E7 & & 16 & 16.00 & 5.87 & 5.78 & 79.66 & 52.09 \\
\hline FZ & & 32 & 8.00 & 4.24 & 4.38 & 41.17 & 27.10 \\
\hline & 15 & 25 & 10.24 & 5.46 & 5.93 & 57.97 & 37.15 \\
\hline & & 16 & 16.00 & 7.16 & 7.33 & 82.97 & 53.07 \\
\hline & & 32 & 8.00 & 4.03 & 4.01 & 37.67 & 25.54 \\
\hline & 30 & 25 & 10.24 & 4.94 & 5.37 & 46.28 & 34.79 \\
\hline & & 16 & 16.00 & 6.34 & 6.07 & 74.70 & 50.78 \\
\hline F3 & & 32 & 8.00 & 4.19 & 4.27 & 40.52 & 28.41 \\
\hline & 15 & 25 & 10.24 & 5.50 & 5.88 & 55.07 & 39.65 \\
\hline & & 16 & 16.00 & 7.61 & 7.79 & 85.66 & 55.20 \\
\hline & & 32 & 8.00 & 4.12 & 4.06 & 40.19 & 25.68 \\
\hline & 30 & 25 & 10.24 & 4.99 & 5.46 & 47.27 & 33.20 \\
\hline $\mathrm{F} 4$ & & 16 & 16.00 & 5.75 & 5.82 & 79.77 & 53.98 \\
\hline $\mathrm{F} 4$ & & 32 & 8.00 & 4.26 & 4.27 & 40.26 & 28.86 \\
\hline & 15 & 25 & 10.24 & 5.62 & 5.51 & 57.41 & 36.92 \\
\hline & & 16 & 16.00 & 7.79 & 7.54 & 81.14 & 53.36 \\
\hline & & 32 & 8.00 & 4.00 & 4.11 & 37.71 & 24.28 \\
\hline & 30 & 25 & 10.24 & 5.11 & 4.95 & 46.09 & 33.17 \\
\hline E7 & & 16 & 16.00 & 5.74 & 6.21 & 72.37 & 51.65 \\
\hline $\mathrm{F} /$ & & 32 & 8.00 & 4.22 & 4.34 & 40.99 & 28.87 \\
\hline & 15 & 25 & 10.24 & 5.69 & 5.59 & 56.10 & 38.96 \\
\hline & & 16 & 16.00 & 7.54 & 7.48 & 82.37 & 53.26 \\
\hline & & 32 & 8.00 & 4.19 & 4.05 & 39.88 & 26.16 \\
\hline & 30 & 25 & 10.24 & 4.96 & 5.34 & 47.83 & 33.38 \\
\hline F8 & & 16 & 16.00 & 5.79 & 5.84 & 78.88 & 49.62 \\
\hline F8 & & 32 & 8.00 & 4.41 & 4.18 & 39.33 & 28.14 \\
\hline & 15 & 25 & 10.24 & 5.51 & 5.87 & 57.50 & 40.21 \\
\hline & & 16 & 16.00 & 7.86 & 7.37 & 81.68 & 52.04 \\
\hline & & 32 & 8.00 & 3.83 & 4.07 & 37.83 & 26.51 \\
\hline & 30 & 25 & 10.24 & 5.45 & 5.03 & 44.36 & 32.48 \\
\hline & & 16 & 16.00 & 5.92 & 6.16 & 76.59 & 51.37 \\
\hline$C Z$ & & 32 & 8.00 & 4.14 & 4.16 & 39.28 & 26.56 \\
\hline & 15 & 25 & 10.24 & 5.73 & 5.49 & 57.36 & 40.09 \\
\hline & & 16 & 16.00 & 7.63 & 7.86 & 83.35 & 52.51 \\
\hline
\end{tabular}

TABLE VI. MEASUREMENT ERRORS AND REDUCTION OF MEASUREMENT TIME WHEN REDUCED NUMBER OF EPOCHS IS INCLUDED IN MEASUREMENT (THERE IS REDUCTION OF MEASUREMENT TIME COMPARING TO STANDARD MEASUREMENT METHOD). H IS THE NUMBER OF HARMONICS MEASURED BY DSMI MODULE (LOCATIONS: C3, C4, P3, P4, A2, VEOG, AND HEOG).

\begin{tabular}{|c|c|c|c|c|c|c|c|}
\hline $\begin{array}{c}\text { Measurement } \\
\text { location }\end{array}$ & $\begin{array}{c}\text { Number of } \\
\text { harmonics } \\
\text { measured by } \\
\text { DSMI module }\end{array}$ & $\begin{array}{c}\text { Number of } \\
\text { epochs }\end{array}$ & $\begin{array}{c}\text { Ratio of } \\
\text { measurement } \\
\text { time } \\
\text { reduction }\end{array}$ & $\begin{array}{c}\text { Average } \\
\text { relative error } \\
\text { of latency } \\
(\%)\end{array}$ & $\begin{array}{c}\text { Standard } \\
\text { deviation of } \\
\text { relative error of } \\
\text { latency }(\%)\end{array}$ & $\begin{array}{c}\text { Average } \\
\text { relative } \\
\text { error of } \\
\text { amplitude } \\
(\%) \\
\end{array}$ & $\begin{array}{c}\text { Standard } \\
\text { deviation of } \\
\text { relative error of } \\
\text { amplitude }(\%)\end{array}$ \\
\hline \multirow[t]{6}{*}{$\mathrm{C} 3$} & \multirow{3}{*}{30} & 32 & 8.00 & 3.81 & 3.93 & 39.96 & 25.69 \\
\hline & & 25 & 10.24 & 5.34 & 5.14 & 47.09 & 32.52 \\
\hline & & 16 & 16.00 & 5.93 & 5.90 & 76.85 & 49.85 \\
\hline & \multirow{3}{*}{15} & 32 & 8.00 & 4.38 & 4.23 & 40.22 & 26.39 \\
\hline & & 25 & 10.24 & 5.43 & 5.44 & 58.80 & 39.04 \\
\hline & & 16 & 16.00 & 7.17 & 7.46 & 83.19 & 50.70 \\
\hline \multirow[t]{6}{*}{$\mathrm{C} 4$} & \multirow{3}{*}{30} & 32 & 8.00 & 4.15 & 3.86 & 39.49 & 24.32 \\
\hline & & 25 & 10.24 & 5.30 & 5.16 & 48.12 & 34.31 \\
\hline & & 16 & 16.00 & 5.78 & 6.20 & 74.09 & 50.61 \\
\hline & \multirow{3}{*}{15} & 32 & 8.00 & 4.23 & 4.34 & 42.62 & 27.39 \\
\hline & & 25 & 10.24 & 5.75 & 5.67 & 53.80 & 38.70 \\
\hline & & 16 & 16.00 & 7.50 & 7.71 & 88.29 & 52.87 \\
\hline \multirow[t]{5}{*}{ P3 } & \multirow{3}{*}{30} & 32 & 8.00 & 4.15 & 3.95 & 37.56 & 26.23 \\
\hline & & 25 & 10.24 & 5.18 & 5.43 & 48.05 & 34.24 \\
\hline & & 16 & 16.00 & 5.95 & 5.81 & 78.36 & 49.73 \\
\hline & \multirow{2}{*}{15} & 32 & 8.00 & 4.15 & 4.37 & 39.21 & 27.56 \\
\hline & & 25 & 10.24 & 5.83 & 5.79 & 53.91 & 40.33 \\
\hline
\end{tabular}




\begin{tabular}{|c|c|c|c|c|c|c|c|}
\hline $\begin{array}{l}\text { Measurement } \\
\text { location }\end{array}$ & $\begin{array}{c}\text { Number of } \\
\text { harmonics } \\
\text { measured by } \\
\text { DSMI module }\end{array}$ & $\begin{array}{l}\text { Number of } \\
\text { epochs }\end{array}$ & $\begin{array}{c}\text { Ratio of } \\
\text { measurement } \\
\text { time } \\
\text { reduction }\end{array}$ & $\begin{array}{c}\text { Average } \\
\text { relative error } \\
\text { of latency } \\
(\%)\end{array}$ & $\begin{array}{c}\text { Standard } \\
\text { deviation of } \\
\text { relative error of } \\
\text { latency }(\%)\end{array}$ & $\begin{array}{c}\text { Average } \\
\text { relative } \\
\text { error of } \\
\text { amplitude } \\
(\%)\end{array}$ & $\begin{array}{c}\text { Standard } \\
\text { deviation of } \\
\text { relative error of } \\
\text { amplitude }(\%)\end{array}$ \\
\hline & & 16 & 16.00 & 7.69 & 7.33 & 88.63 & 54.88 \\
\hline \multirow[t]{6}{*}{$\mathrm{P} 4$} & \multirow{3}{*}{30} & 32 & 8.00 & 3.98 & 3.93 & 39.26 & 26.17 \\
\hline & & 25 & 10.24 & 5.46 & 5.05 & 43.80 & 32.47 \\
\hline & & 16 & 16.00 & 6.33 & 5.75 & 74.47 & 49.49 \\
\hline & \multirow{3}{*}{15} & 32 & 8.00 & 4.30 & 4.05 & 42.61 & 27.83 \\
\hline & & 25 & 10.24 & 5.85 & 5.68 & 53.40 & 36.72 \\
\hline & & 16 & 16.00 & 7.41 & 7.64 & 88.00 & 52.18 \\
\hline \multirow[t]{6}{*}{ A2 } & \multirow{3}{*}{30} & 32 & 8.00 & 3.90 & 4.07 & 38.49 & 24.38 \\
\hline & & 25 & 10.24 & 5.02 & 5.48 & 47.54 & 33.53 \\
\hline & & 16 & 16.00 & 6.23 & 6.13 & 72.45 & 51.31 \\
\hline & \multirow{3}{*}{15} & 32 & 8.00 & 4.23 & 4.26 & 41.93 & 29.06 \\
\hline & & 25 & 10.24 & 5.96 & 5.79 & 55.31 & 38.65 \\
\hline & & 16 & 16.00 & 7.14 & 7.25 & 85.26 & 52.84 \\
\hline \multirow[t]{6}{*}{ VEOG } & \multirow{3}{*}{30} & 32 & 8.00 & 3.95 & 4.14 & 39.50 & 26.36 \\
\hline & & 25 & 10.24 & 5.10 & 5.36 & 45.03 & 33.62 \\
\hline & & 16 & 16.00 & 5.82 & 6.23 & 74.93 & 50.40 \\
\hline & \multirow{3}{*}{15} & 32 & 8.00 & 4.41 & 4.06 & 40.36 & 26.71 \\
\hline & & 25 & 10.24 & 5.80 & 5.80 & 58.60 & 36.65 \\
\hline & & 16 & 16.00 & 7.61 & 7.81 & 86.52 & 55.50 \\
\hline \multirow[t]{6}{*}{ HEOG } & \multirow{3}{*}{30} & 32 & 8.00 & 4.13 & 4.16 & 38.81 & 24.67 \\
\hline & & 25 & 10.24 & 5.08 & 5.32 & 44.66 & 32.59 \\
\hline & & 16 & 16.00 & 6.21 & 5.81 & 79.68 & 53.07 \\
\hline & \multirow{3}{*}{15} & 32 & 8.00 & 4.21 & 4.32 & 42.47 & 28.35 \\
\hline & & 25 & 10.24 & 5.88 & 5.45 & 58.72 & 38.15 \\
\hline & & 16 & 16.00 & 7.11 & 7.41 & 88.49 & 55.30 \\
\hline
\end{tabular}

TABLE VII. AVERAGE MEASUREMENT ERRORS OF ALL CHANNELS.

\begin{tabular}{|c|c|c|c|c|c|c|}
\hline $\begin{array}{c}\text { Number of } \\
\text { harmonics measured } \\
\text { by DSMI module }\end{array}$ & $\begin{array}{c}\text { Number of } \\
\text { epochs }\end{array}$ & $\begin{array}{c}\text { Ratio of } \\
\text { measurement } \\
\text { time reduction }\end{array}$ & $\begin{array}{c}\text { Average } \\
\text { relative error of } \\
\text { latency (\%) }\end{array}$ & $\begin{array}{c}\text { Standard deviation } \\
\text { of relative error of } \\
\text { latency (\%) }\end{array}$ & $\begin{array}{c}\text { Average relative } \\
\text { error of } \\
\text { amplitude (\%) }\end{array}$ & $\begin{array}{c}\text { Standard } \\
\text { deviation of } \\
\text { relative error } \\
\text { of amplitude } \\
\text { (\%) }\end{array}$ \\
\hline \multirow{2}{*}{30} & 32 & 8.00 & 4.03 & 4.11 & 38.84 & 25.43 \\
\cline { 2 - 7 } & 25 & 10.24 & 5.18 & 5.26 & 46.23 & 33.31 \\
\hline \multirow{2}{*}{15} & 16 & 16.00 & 6.01 & 5.98 & 76.03 & 51.17 \\
\cline { 2 - 7 } & 32 & 8.00 & 4.26 & 4.33 & 50.78 & 27.77 \\
\cline { 2 - 7 } & 25 & 10.24 & 5.71 & 5.72 & 85.63 & 38.68 \\
\hline
\end{tabular}

The model is primarily based on a MATLAB implementation of a DSMI module and software, but also includes EEGLAB [35] and ERPLAB [36] tools for obtaining the referential data from a referential database. The main simulation program enables simulations of different designs of the measurement system by varying the number of the measured harmonics and the number of EEG epochs included in the measurement.

\section{CONCLUSIONS}

In the performed simulations, [34] is used as the source of the referential database. Simulations covered 8 different designs of the measurement system. In those designs, the implemented number of measured harmonics was 15 or 30 , and the implemented number of epochs included in the measurement was $256,32,25$ or 16.

The results from Table III show that the developed system can be used primarily for measurement of the peak latency time. However, it can be used for measuring the peak amplitude only if the requirements for the measurement accuracy are not of high priority.

In Table VII, it is shown how the average relative error of latency increases with the increase of the reduction ratio. These results indicate probably the most interesting characteristics of the developed measurement system.
Although the measurement errors increase with the increase of the measurement time reduction ratio (which is the indicator of shortening the total measurement time), the measurement errors for the peak latency times are relatively small, thus making this system useful for practical implementations when latency is the most interesting parameter and the requirements for short measurement time are of high priority.

The total measurement time for measurement of the ERP peak amplitude and latency based on a standard measurement system equals the number of epochs multiplied by the duration of one epoch. In a referential experiment, where the number of epochs is 256 and the duration of one epoch is $1 \mathrm{~s}$, the total measurement time equals $256 \times 1 \mathrm{~s}=$ $256 \mathrm{~s}$. With the new measurement system, this time can be reduced down to 16 seconds with the average relative error of latency equaling $6.01 \%$ and the standard deviation of this error equaling $5.98 \%$.

\section{CONFLICTS OF INTEREST}

The authors declare that they have no conflicts of interest.

\section{REFERENCES}

[1] D. L. Schomer and F. H. Lopes da Silva, Niedermeyer's Electroencephalography: Basic Principles, Clinical Applications, 
and Related Fields, 7th ed. Oxford University Press, 2017. DOI: 10.1093/med/9780190228484.001.0001.

[2] M. Teplan, A. Krakovská, and S. Štolc, "Short-term effects of audiovisual stimulation on EEG", Measurement Science Review, vol. 6, sec. 2, no. 4, pp. 67-70, 2006.

[3] K. Šušmáková and A. Krakovská, "Classification of waking, sleep onset and deep sleep by single measures", Measurement Science Review, vol. 7, sec. 2, no. 4, pp. 34-38, 2007.

[4] G. Vrbancic and V. Podgorelec, "Automatic classification of motor impairment neural disorders from EEG signals using deep convolutional neural networks", Elektronika Ir Elektrotechnika, vol. 24, no. 4, pp. 3-7, 2018. DOI:10.5755/j01.eie.24.4.21469.

[5] J. X. Chen, D. M. Jiang, and Y. N. Zhang, "A hierarchical bidirectional GRU model with attention for EEG-based emotion classification", IEEE Access, vol. 7, pp. 118530-118540, 2019. DOI: 10.1109/ACCESS.2019.2936817.

[6] T. Song, W. Zheng, P. Song, and Z. Cui, "EEG emotion recognition using dynamical graph convolutional neural networks", IEEE Transactions on Affective Computing. DOI: 10.1109/TAFFC.2018.2817622.

[7] X. Zhang, L. Yao, Q. Z. Sheng, S. S. Kanhere, T. Gu, and D. Zhang, "Converting your thoughts to texts: Enabling brain typing via deep feature learning of EEG signals", in Proc. of 2018 IEEE International Conference on Pervasive Computing and Communications (PerCom), Athens, 2018, pp. 1-10. DOI: 10.1109/PERCOM.2018.8444575.

[8] A. D. Nordin, W. D. Hairston, and D. P. Ferris, "Faster gait speeds reduce alpha and beta EEG spectral power from human sensorimotor cortex", IEEE Transactions on Biomedical Engineering, vol. 67, no. 3, pp. 842-853, 2020. DOI: 10.1109/TBME.2019.2921766.

[9] R. Foong et al., "Assessment of the efficacy of EEG-based MI-BCI with visual feedback and EEG correlates of mental fatigue for upperlimb stroke rehabilitation", IEEE Transactions on Biomedical Engineering, vol. 67, no. 3, pp. 786-795, 2020. DOI: 10.1109/TBME.2019.2921198.

[10] N. Michielli, U. Rajendra Acharya, and F. Molinari, "Cascaded LSTM recurrent neural network for automated sleep stage classification using single-channel EEG signals", Computers in Biology and Medicine, vol. 106, pp. 71-81, 2019. DOI: 10.1016/j.compbiomed.2019.01.013.

[11] Z. Gao, X. Wang, Y. Yang, Ch. Mu, Q. Cai, W. Dang, and S. Zuo "EEG-based spatio-temporal convolutional neural network for driver fatigue evaluation", IEEE Transactions on Neural Networks and Learning Systems, vol. 30, no. 9, pp. 2755-2763, Sept. 2019. DOI: 10.1109/TNNLS.2018.2886414.

[12] S. J. Luck, An Introduction to Event-Related Potentials and Their Neural Origins. MIT Press, 2005.

[13] M. Cecchi, D. K. Moore, C. H. Sadowsky, P. R. Solomon, P. M. Doraiswamy, C. D. Smith, G. A. Jicha, A. E. Budson, S. E. Arnold, and K. C. Fadem, "A clinical trial to validate event-related potential markers of Alzheimer's disease in outpatient settings, Alzheimer's \& Dementia: Diagnosis, Assessment \& Disease Monitoring, vol. 1, pp. 387-394, 2015. DOI: 10.1016/j.dadm.2015.08.004.

[14] A. Anticevic, K. Haut, J. D. Murray et al., "Association of thalamic dysconnectivity and conversion to psychosis in youth and young adults at elevated clinical risk", JAMA Psychiatry, vol. 72, no. 9, pp. 882-891, 2015. DOI: 10.1001/jamapsychiatry.2015.0566.

[15] F. Barcelo and P. S. Cooper, "An information theory account of late frontoparietal ERP positivities in cognitive control", Psychophysiology, vol. 55, no. 3, 2018. DOI: 10.1111/psyp.12814.

[16] J. S. Moser, A. Dougherty, W. I. Mattson et al., "Third-person selftalk facilitates emotion regulation without engaging cognitive control: Converging evidence from ERP and fMRI", Scientific Reports, vol. 7, p. 4519, 2017. DOI: $10.1038 / \mathrm{s} 41598-017-04047-3$.

[17] Y. K. Chang, B. L. Alderman, C. H. Chu, C. C. Wang, T. F. Song, and F. T. Chen, "Acute exercise has a general facilitative effect on cognitive function: A combined ERP temporal dynamics and BDNF study", Psychophysiology, vol. 54, no. 2, pp. 289-300, 2017. DOI: 10.1111/psyp. 12784

[18] D. Nurseitov, A. Serekov, A. Shintemirov, and B. Abibullaev, "Design and evaluation of a P300-ERP based BCI system for realtime control of a mobile robot", in Proc. of 5th International Winter Conference on Brain-Computer Interface (BCI), Sabuk, 2017, pp.
115-120. DOI: 10.1109/IWW-BCI.2017.7858177.

[19] Z. Ma and T. Qiu, "Performance improvement of ERP-based braincomputer interface via varied geometric patterns", Medical \& Biological Engineering \& Computing, vol. 55, pp. 2245-2256, 2017. DOI: $10.1007 / \mathrm{s} 11517-017-1671-5$

[20] M. K. I. Molla, N. Morikawa, M. R. Islam, and T. Tanaka, "Dataadaptive spatiotemporal ERP cleaning for single-trial BCI implementation", IEEE Transactions on Neural Systems and Rehabilitation Engineering, vol. 26, no. 7, pp. 1334-1344, Jul. 2018. DOI: $10.1109 /$ TNSRE.2018.2844109.

[21] B. MacDonald and R. J. Barry, "Significance and novelty effects in single-trial ERP components and autonomic responses", International Journal of Psychophysiology, vol. 117, pp. 48-64, 2017. DOI: 10.1016/j.ijpsycho.2017.03.007.

[22] S. K. Haider, A. Jiang, M. A. Jamshed, H. Pervaiz, and S. Mumtaz, "Performance enhancement in P300 ERP single trial by machine learning adaptive denoising mechanism", IEEE Networking Letters, vol. 1, no. 1, pp. 26-29, 2019. DOI: 10.1109/LNET.2018.2883859.

[23] J. Von Neumann, "Probabilistic logic and the synthesis of reliable organisms from unreliable components", in C. Shannon (Eds.), Automata Studies. Princeton, USA, Princeton University Press, 1956, pp. $43-98$

[24] M. F. Wagdy, W.-M. Ng, "Validity of uniform quantization error model for sinusoidal signals without and with dither", IEEE Transactions on Instrumentation and Measurement, vol. 38, no. 3 , pp. 718-722, 1989. DOI: 10.1109/19.32180.

[25] M. Kamenský and K. Kováč, "Correction of ADC errors by additive iterative method with dithering", Measurement Science Review, vol. 11, no. 1, pp. 15-18, 2011. DOI: 10.2478/v10048-011-0004-3.

[26] V. Vujičić, S. Milovančev, M. Pešaljević, D. Pejić, and I. Župunski, "Low frequency stochastic true RMS instrument", IEEE Transactions on Instrumentation and Measurement, vol. 48, no. 2, pp. 467-470, 1999. DOI: $10.1109 / 19.769630$.

[27] D. Pejic and V. Vujicic, "Accuracy limit of high-precision stochastic watt-hour meter", IEEE Transactions on Instrumentation and Measurement, vol. 49, no. 3, pp. 617-620, 2000. DOI: $10.1109 / 19.850404$.

[28] B. Santrač, M. A. Sokola, Z. Mitrović, I. Župunski, and V. Vujičić, "A novel method for stochastic measurement of harmonics at low signal-to-noise ratio", IEEE Transactions on Instrumentation and Measurement, vol. 58, no. 10, pp. 3434-3441, 2009. DOI: 10.1109/TIM.2009.2017661.

[29] V. Pjevalica and V. Vujičić, "Further generalization of the lowfrequency true-RMS instrument", IEEE Transactions on Instrumentation and Measurement, vol. 59, no. 3, pp. 736-744, 2010. DOI: 10.1109/IMTC.2005.1604291.

[30] P. M. Sovilj, S. S. Milovančev, and V. Vujičić, "Digital stochastic measurement of a nonstationary signal with an example of EEG signal measurement", IEEE Transactions on Instrumentation and Measurement, vol. 60, no. 9, pp. 3230-3232, 2011. DOI: 10.1109/TIM.2011.2128670

[31] V. Pjevalica, N. Pjevalica, I. Kaštelan, and N. Petrović, "Acceleration of digital stochastic measurement simulation based on concurrent programming", Elektronika ir Elektrotechnika, vol. 24, no. 6, pp. 2127, 2018. DOI: 10.5755/j01.eie.24.6.22284.

[32] N. Pjevalica, V. Pjevalica, and N. Petrović, "Advances in concurrent computing for digital stochastic measurement simulation", Journal of Circuits, Systems and Computers, vol. 29, no. 2, pp. 1-20, 2020. DOI: $10.1142 / \mathrm{S} 0218126620500334$.

[33] V. Vujičić, B. Ličina, D. Pejić, P. Sovilj, and A. Radonjić, "Stochastic measurement of wind power using a two-bit A/D converter", Measurement, vol. 152, pp. 21-27, 2020. DOI: 10.1016/j.measurement.2019.107184.

[34] S. J. Luck, E. S. Kappenman, R. L. Fuller, B. Robinson, A Summerfelt, and J. M. Gold, "Impaired response selection in schizophrenia: Evidence from the P3 wave and the lateralized readiness potential", Psychophysiology, vol. 46, pp. 776-786, 2009. DOI: $10.1111 /$ j.1469-8986.2009.00817.x.

[35] EEGLAB Wiki Tutorial as a PDF book. [Online]. Available: http://sccn.ucsd.edu/eeglab/

[36] C. Markley, S. Luck, and J. Lopez-Calderon, ERPLAB Toolbox User's Manual Version 3.0, 10 October 2012. [Online]. Available: http://erpinfo.org/erplab/ 